\title{
List of Currencies
}

Brunei Darussalam

Canada

Chile

Mexico

New Zealand

Papua New Guinea

Peru

Philippines

Russia

Singapore

Vietnam

\author{
B \$, dollar \\ C\$, dollar \\ $\mathrm{P}$, peso \\ $P$, peso \\ NZ\$, dollar \\ $\mathrm{K}$, kina \\ S/., neuvo sol \\ $\mathrm{P}$, peso \\ $R$, rouble \\ S\$, dollar \\ VND, dollar
}

xiii 
